\title{
AS CIDADES QUE EDUCAM: ESPAÇOS EDUCATIVOS NÃO-FORMAIS COMO ALTERNATIVA PARA FORMAÇÃO DE CIDADÃOS PROTAGONISTAS RESPONSÁVEIS
}

\author{
Cleoci Werle Rockenbach ${ }^{1}$ \\ Luís Henrique Teixeira Franqui
}

Resumo: O movimento das Cidades educadoras preconiza que são cidades que educam aquelas que visam, fundamentalmente, à formação, promoção e desenvolvimento de todos os seus habitantes, ocupando-se com prioridade das crianças e dos jovens, mas incorporando, em suas atividades, pessoas de todas as faixas etárias, numa verdadeira formação continuada ao longo da vida. $\mathrm{O}$ fato de uma cidade não integrar o rol oficial das Cidades Educadoras, como é o caso de Eugênio de Castro, não exclui a possibilidade do estudo acerca de iniciativas positivas que venham ao encontro dos objetivos do movimento. Considerando que o estímulo ao protagonismo responsável abordado na política de assistência social de Eugênio de Castro comunica-se claramente com a principiologia do movimento global Cidades Educadoras, apresenta-se o trabalho realizado a fim de exemplificar a possibilidade de implantação desses princípios em uma pequena cidade, mesmo não integrando o movimento internacional, e os resultados positivos alcançados com o trabalho.

Palavras-chave: Assistência Social; Cidades educadoras; Cidadania; Protagonismo Responsável.

\section{The cities that educate: non-formal educational spaces as an alternative for the formation of responsible protagonist citizens}

\begin{abstract}
The movement of educating Cities advocates that they are cities that educate those that basically aim at the formation, promotion and development of all its inhabitants, occupying itself with priority of the children and young people, but incorporating, in their activities, people of all The age groups, in a truly lifelong continuing education. The fact that a city does not integrate the official role of Educating Cities, such as Eugênio de Castro, does not exclude the possibility of studying positive initiatives that meet the goals of the movement. Considering that the stimulus to the responsible protagonism addressed in the policy of social assistance of Eugênio de Castro communicates clearly with the principiology of the global movement Educating Cities, the work is presented to exemplify the possibility of implantation of these principles in a small city, Even without integrating the international movement, and the positive results achieved with the work.
\end{abstract}

\footnotetext{
${ }^{1}$ Ciências Humana - psicologia UFFS - Universidade Federal da Fronteira Sul.

${ }^{2}$ Ciências Humanas - Direito UFFS - Universidade Federal da Fronteira Sul.
} 
Keywords: Social assistance; Educating cities; Citizenship; Responsible Protagonism.

Resúmen: Muchos estudios han señalado que el emprendimiento es fundamental para el desarrollo de la economía. Incluso antes de definir lo que es empreender ciertas prácticas ya eran determinantes para la supervivencia humana. El artículo busca, a través de un estudio cuantitativo y cualitativo en micro y pequeñas empresas del centro comercial de la ciudad de Macapá-AP, analizar la influencia de las variables necesidad y oportunidad para la aparición de nuevas empresas empresas. Los resultados sugieren que estos dos factores son importantes para que se presenten tales empresas, pero la necesidad se mostró considerablemente más decisiva frente a otros factores para el ingreso de individuos en el comercio de dicha región.

Palabras clave: Social assistance; Educating cities; Citizenship; Responsible Protagonism.

\section{INTRODUÇÃO}

As cidades, independente do tamanho ou localização, oferecem muitos elementos para a formação integral e permanente dos seus habitantes, enriquecendo a sua vida. Dentre as diversas funções de uma cidade, a função educadora visa à formação e ao desenvolvimento de todos os cidadãos, incorporando pessoas de todas as idades, numa formação ao longo de toda a vida. Apresenta-se, no desenvolvimento do artigo, um breve histórico sobre o movimento denominado Cidades Educadoras, as suas principais características e princípios e como esses elementos podem ser observados no trabalho realizado em um pequeno município da região. Embora se compreenda que o movimento das cidades educadoras seja algo complexo e muito abrangente, utilizamos, de modo bastante simplificado, essa concepção para referenciar uma experiência de trabalho realizada junto à política de assistência social. Realizou-se um estudo de caso do Centro de Referência em Assistência Social - CRAS de Eugênio de Castro, onde se desenvolve uma experiência de educação permanente e promoção de cidadania, com famílias de baixa renda,apresentando-se alguns resultados obtidos com o trabalho.

\section{As cidades que educam}

Com a realização do $1^{\circ}$ Congresso Internacional de Cidades Educadoras, no ano de 1990, em Barcelona (Espanha), iniciou-se o movimento denominado "Cidades 
Educadoras", com o objetivo comum de trabalhar projetos e atividades para melhorar a qualidade de vida em suas localidades. O movimento foi formalizado no $3^{\circ}$ Congresso da Associação Internacional de Bolonha (Itália), em 1994.

A Carta das Cidades Educadoras, cuja proposta definitiva foi formatada no Congresso Internacional de Gênova (Itália), lembra que "elas partiam do princípio que o desenvolvimento dos seus habitantes não podia ser deixado ao acaso" (CARTA, 2004, sp). A Carta tem como base alguns dos principais estatutos internacionais de direitos humanos e de educação e cultura, como a Declaração Universal dos Direitos do Homem (1948), o Pacto Internacional dos Direitos Econômicos, Sociais e Culturais (1966), a Declaração Mundial da Educação para Todos (1990), a Cimeira Mundial para a Infância (1990) e a Declaração Universal sobre DiversidadeCultural (2001), visando, fundamentalmente, à formação, promoção e desenvolvimento de todos os seus habitantes, ocupando-se com prioridade das crianças e dos jovens, mas incorporando, em suas atividades, pessoas de todas as faixas etárias, numa verdadeira formação continuada ao longo da vida.

Como a própria Carta enfatiza, mais do que uma cidade estar efetivamente participando do movimento, "hoje mais do que nunca as cidades, grandes ou pequenas, dispõem de inúmeras possibilidades educadoras" (CARTA, 2004, sp). O fato de uma cidade não integrar o rol oficial das Cidades Educadoras, como é o caso de Eugênio de Castro, não exclui a possibilidade do debate acerca de iniciativas positivas que venham ao encontro dos objetivos do movimento, como promover "a formação, promoção e o desenvolvimento de todos os seus habitantes" (2004, sp). Até mesmo pelo fato de existirem razões que justificam a função de uma cidade educadora, de ordem social, econômica e política, que são:

Primeiro investir na educação de cada pessoa, de maneira a que esta seja cada vez mais capaz de exprimir, afirmar e desenvolver o seu potencial humano, assim como a sua singularidade, a sua criatividade e a sua responsabilidade. Segundo, promover as condições de plena igualdade para que todos possam sentir-se respeitados e serem respeitadores, capazes de diálogo. Terceiro, conjugar todos os factores possíveis para que se possa construir, cidade a cidade, uma verdadeira sociedade do conhecimento sem exclusões, para a qual é preciso providenciar, entre outros, o acesso fácil de toda a população às tecnologias da informação e das comunicações que permitam o seu desenvolvimento (CARTA, 2004, sp). 
Cabe uma reflexão sobre o fato que as cidades educadoras possuem “instituições educativas formais, intervenções não formais (de uma intencionalidade educadora para além da educação formal) e informais (não intencionais ou planificadas)" (CARTA, 2004, sp). No caso, a experiência relatada em Eugênio de Castro, mesmo não se enquadrando numa instituição educacional formal, também merece atenção e estudo, pois o espírito de cooperação tão fomentado nas cidades educadoras está presente nas atividades desenvolvidas no Centro de Referência em Assistência Social (CRAS).

\section{Princípios}

A Associação Internacional de Cidades Educadoras (AICE) salienta que entre os princípios gerais das Cidades Educadoras estão

Trabalhar a escola como espaço comunitário;

Trabalhar a cidade como grande espaço educador;

Aprender na cidade, com a cidade e com as pessoas;

Valorizar o aprendizado vivencial;

Priorizar a formação de valores. (ASSOCIAÇÃO, 2016, sp)

Na Carta, os 20 princípios do movimento são pormenorizados, divididos em três blocos: O direito a uma cidade educadora, O compromisso da cidade e Ao serviço integral das pessoas.

Logo no primeiro princípio, garante-se que "todos os habitantes de uma cidade terão o direito de desfrutar, em condições de liberdade e igualdade, os meios e oportunidades de formação, entretenimento e desenvolvimento pessoal que ela thes oferece" (CARTA, 2004, sp). Aqui, cabe um questionamento a respeito da "liberdade" [grifos nossos], tomando-se o exemplo da experiência desenvolvida em Eugênio de Castro, onde há certa condicionante para que a pessoa tenha acesso aos benefícios da Política Municipal de Assistência Social, numa espécie de contrapartida ao poder público, fazendo-se presente nos encontros de formação. João Oliveira Correia da Silva, analisando a obra "Desenvolvimento como liberdade", de Amartya Sen, frisa que 
...a importância nuclear da liberdade individual no conceito de desenvolvimento relaciona-se com duas razões: a avaliação e a eficácia. $\mathrm{O}$ sucesso de uma sociedade deve ser avaliado pelas liberdades concretas de que gozam os seus membros. Esta perspectiva difere das que se centram na utilidade, na liberdade de procedimentos, ou no rendimento real.

Ter liberdade para fazer coisas a que se atribui valor tem valor por si mesmo, e melhora as condições para obter resultados. A liberdade é não só a base da avaliação do sucesso do fracasso, mas também a principal determinante da iniciativa e da eficácia social (SILVA, 2016).

A liberdade das pessoas é condicionada pelas normas e regulamentos que regem o convívio social. Desse modo, a liberdade acaba sendo condicionada por fatores externos, que exigem de nós uma conduta dentro de padrões estabelecidos, fazendo-nos abandonar, portanto, a existência de uma suposta liberdade absoluta. Essa reflexão é necessária, pois ações em prol dos cidadãos, condicionando eventuais eficácias e avaliações dos programas de assistência social à participação compulsória, como é o caso, não retira a liberdade, nem afeta o exercício da cidadania pelos envolvidos nas atividades do CRAS.

Outro princípio relevante da Carta determina que "as políticas municipais de caráter educativo devem ser sempre entendidas no seu contexto mais amplo inspirado nos princípios de justiça social, de civismo democrático, a qualidade de vida e da promoção dos seus habitantes" (CARTA, 2004, sp).

Dois outros princípios são igualmente contemplados na iniciativa eugeniocastrense: "a cidade educadora deverá fomentar a participação cidadã com uma perspectiva crítica e co-responsável” e "a cidade deverá procurar que todas as famílias recebam uma formação que lhes permitirá ajudar os seus filhos a crescer e a apreender a cidade, num espírito de respeito mútuo" (CARTA, 2004, sp).

Percebe-se que o estímulo ao protagonismo responsável na política de assistência social de Eugênio de Castro comunica-se claramente com a principiologia do movimento global Cidades Educadoras.

\section{Educar para a cidadania}

Citado por Moacir Gadotti, Paulo Freire afirma que "enquanto educadora, a Cidade é também educanda" (apudGADOTTI, 2006, p. 133). Essa reflexão inicial é oportuna, pois demonstra que educação é uma via de mão dupla. Um professor, quando 
leciona, está em constante processo de autoeducação, não apenas quando prepara a aula, mas também como reflexo das experiências vivenciadas junto aos alunos. A mesma lógica pode ser usada para a cidade, que educa e também cresce com as experiências por seus cidadãos.

A educação para a cidadania passa, primeiramente, por uma cidadania plena, envolvendo os seus vários tipos: política, participação numa comunidade política; social, justiça como exigência ética da sociedade de bem viver; econômica, transformação produtiva com equidade; civil, afirmação de valores como liberdade, igualdade e solidariedade; e intercultural, interculturalidade como projeto ético e político ao etnocentrismo (GADOTTI, 2006, p. 134).

Numa cidade que educa, como leciona Gadotti, os habitantes gozam "das mesmas oportunidades de formação, desenvolvimento pessoal e de entretenimento que ela oferece". E mais. Para ele, "a cidade oferecerá aos pais uma formação que lhes permita ajudar os seus filhos a crescer e utilizar a cidade num espírito de respeito mútuo" (2006. p. 134). E, neste aspecto, o trabalho desenvolvido no CRAS propõe-se a estimular os pais a dialogar com os filhos, oferecendo-lhes ferramentas que possam ser utilizadas para estimular o crescimento pleno.

Como espaço das diferenças que é, precisamos de uma cidade com uma pedagogia que nos estimule a observá-la, a descobri-la, além de aprender e conviver com ela (GADOTTI, 2006, p. 139). É primordial que, num projeto de futuro, trabalhemos para a construção de uma cidade educadora e educanda, que possibilite a emancipação de seus habitantes, através de práticas cada vez mais humanas e solidárias.

\section{Apresentação}

Tendo em vista essa função educadora das cidades, apresenta-se uma experiência de formação continuada realizada junto ao Centro de Referência em Assistência Social (CRAS) do município de Eugênio de Castro .

O CRAS é a unidade municipal responsável pela oferta do Serviço de Proteção e Atendimento Integral à Família (PAIF), o principal serviço de proteção social básica da Política Nacional de Assistência Social (PNAS). Os objetivos propostos pela Política Nacional de Assistência Social (BRASIL, 2005, p. 16) são o desenvolvimento de potencialidades e aquisições para maior autonomia e protagonismo da pessoa, uma 
política voltada ao "desenvolvimento humano e social e não tuteladora ou assistencialista, ou ainda, tão só provedora de necessidades ou vulnerabilidades sociais". A Assistência Social é uma importante política pública integrante do tripé da seguridade social e, nos seus objetivos, está integrada essa função educadora e de formação permanente. As ações ofertadas às famílias dentro do PAIF podem contribuir para a formação de cidadãos éticos, responsáveis, cientes de seus deveres pessoais e sociais e protagonistas responsáveis pela transformação da própria realidade.

Cada pessoa possui capacidades e potencialidades, mas, devido ao tipo de educação recebida na infância, não é preparada para a entrada na vida em sociedade e para as responsabilidades da vida adulta. A educação recebida não estimula o desenvolvimento do potencial que cada um tem por natureza e torna a pessoa dependente, no início dos genitores, e, mais tarde, do Estado e da sociedade. Em decorrência disso, muitas pessoas ingressam na vida adulta esperando serem assistidas e compensadas naquilo que se consideram incapazes de alcançar.

Conforme Meneghetti (2014, p. 16), "no interior de cada homem há um positivobase em que o ser estabelece o próprio sentido apriórico que universaliza o homem à autorrealização". Em outros termos, no interior do ser humano há um núcleo fundante de positividade que permite a cada um a realização, segundo o próprio potencial. Esse núcleo fundante é um princípio de inteligência que também se constitui como a primeira e incontestável riqueza de cada um. Uma vez que cada pessoa possui esse potencial de natureza e vendo-se ainda um bom número delas em situação de dependência econômica, sendo um peso para o Estado e para a sociedade, depreende-se que o objetivo proposto pela PNAS, de promover a autonomia da pessoa, não está sendo alcançado. Além disso, no convívio cotidiano, muitas vezes, encontram-se pessoas que não se empenham minimamente no dever de estudar, de aprimorar-se, de garantir o próprio sustento e de sua família, conformando-se a uma situação de dependência.

\section{Metodologia}

Compondo a política de Assistência Social do município de Eugênio de Castro, foi instituído o programa de suplementação alimentar, o qual prevê a concessão de cestas básicas para famílias em situação de extrema pobreza. Adotam-se, como parâmetro para o ingresso no programa, os critérios de renda do Programa Bolsa 
Família. A concessão do benefício está condicionada à participação em atividades educativas promovidas pelo CRAS, que consiste em um encontro mensal, reunindo, pelo menos, um membro de cada família.

A organização dos encontros é responsabilidade da assistente social do CRAS que, até o final do ano de 2015, convidava profissionais para abordar assuntos diversos, visando ao repasse de informações e esclarecimentos sobre assuntos considerados relevantes. Nesse ano [2016],contribuíram com o processo de formação: enfermeiro, médico e agente de endemias, da Estratégia de Saúde da Família (ESF), abordando assuntos relacionados à prevenção da saúde; vereador discorrendo sobre direitos e responsabilidades no fornecimento de informações para cadastramento em programas sociais; auxiliar de contabilidade da Secretaria de Finanças orientando sobre orçamento doméstico; conselheiro tutelar esclarecendo sobre o funcionamento e atribuições do Conselho Tutelar; entre outros.

Em janeiro deste ano [2016], adotou-se outra estratégia. Dos encontros com caráter informativo realizados até então, passou-se a uma postura de responsabilização da pessoa. Os encontros passaram a ser não só organizados, mas também conduzidos pela assistente social, voltando-se para o desenvolvimento da pessoa protagonista responsável.

Os encontros têm frequência mensal, com duração aproximada de uma hora, ocorrendo sempre na primeira semana do mês. A cada encontro, participam entre vinte e cinco e trinta pessoas, sendo um membro de cada família beneficiária. A maior parte dos participantes é mulheres, apenas três ou quatro homens participam das reuniões. A idade dos participantes varia de 17 a 58 anos, havendo predominância de jovens até 30 anos.

Tendo em vista o objetivo de estimular o protagonismo responsável e o desenvolvimento das capacidades e potencialidades dos participantes com base no princípio da dignidade humana, utilizou-se como tema norteador a ser trabalhado nos encontros os valores do humanismo histórico: vida ativa, sociabilidade, liberdade e dignidade humana. Com base nesses valores, passou-se a desenvolver debates e abordagens no sentido de responsabilizar cada um pela tarefa de aprimorar a si mesmo, buscar o autodesenvolvimento e empenhar-se para melhorar as condições da própria vida. 


\section{Desenvolvimento}

As desigualdades de renda, situação econômica e posição social entre os indivíduos de uma sociedade são situações comuns, decorrentes da circunstancialidade histórica. No Brasil, essas desigualdades tornaram-se um assunto de grande relevância devido à enorme discrepância existente entre o estrato mais rico e o mais pobre da população. Outro aspecto que diz respeito a toda a sociedade é a face mais perversa dessa desigualdade: a pobreza e as condições subhumanas em que vivem muitas famílias do estrato de menor renda. O nosso sistema socioeconômico, com a sua cultura excessivamente assistencialista, favorece essa acomodação, justificando e valorizando a pobreza. Neste sentido, Meneghetti refere que a própria sociedade, o próprio sistema deve

\footnotetext{
...começar a ensinar a responsabilidade, o sentido de dever, sobretudo em relação a si mesmo e, por consequência, também em relação aos outros, [...] É preciso começar uma indireta pedagogia cultural, sem condenar. Temos que ajudar, pois cada um de nós também é o outro, e quando vejo um homem pobre, um homem doente, sinto-me tocado na minha humanidade e procuro auxiliar, procuro dar ao outro a minha cultura, a minha inteligência, se ele o permite (MENEGHETTI, 2010a, p.51).
}

O fazer dos profissionais da assistência social, muitas vezes, é caracterizado como um processo de ajuda, mas, conforme May (1988, p.17, p. 20), “o processo de ajudar outras pessoas pode na verdade torná-las conformistas e tender à destruição da individualidade". May chama a atenção para o fato que o indivíduo possui potencialidades e características únicas, que são reprimidas e, por isso, deixam de ser vivenciadas pela pessoa. A repressão das potencialidades "levanta a questão da margem de liberdade do ser humano com respeito a suas potencialidades, uma margem onde reside a responsabilidade sobre si mesmo".

Tarefa do operador social, mais do que prover os mínimos sociais como também preconiza a Política Nacional de Assistência Social, é possibilitar que essas potencialidades sejam vivenciadas e responsabilizar a pessoa pelo autodesenvolvimento. Benelli (2014, p. 276) propõe o homem "protagonista na conquista e afirmação de direitos". Porém, a reivindicação de direitos é sempre uma exigência de que outro supra as minhas necessidades, sem que cada um empenhe-se para supri-las por conta própria. Entende-se que o protagonismo responsável consiste em assumir as rédeas da própria 
vida, empenhando-se em primeira pessoa na busca daquilo que se deseja obter. Assim, propõe-se a concepção de homem descrita por Meneghetti (2004, p.129), como "o homem protagonista responsável, baseado numa virtualidade capaz de atuação pessoal no ser".

Segundo Meneghetti, o Humanismo histórico civil italiano permanece o período mais alto que a história viveu para a cultura humanista, cujo ápice ocorreu nos séculos XIV e XV. O humanismo histórico, como esclarece Meneghetti (2010, p. 57, tradução nossa), "encorajava uma atividade social em liberdade e dignidade do homem, ou seja, promovia o desenvolvimento de quatro valores principais: 1) a vida ativa; 2) a sociabilidade; 3 ) a liberdade; e 4) a dignidade do homem”. Sobre sociabilidade, o autor esclarece:

O conceito profundo de "sociabilidade" não implica assistencialismo: não se fala de caridade, porém de responsabilidade. Os assim ditos "pobres" são ajudados a tornar-se, não devem ser substituídos naquilo que podem fazer: é inútil saciá-los, precisa oferecer a eles a cultura que faz superior o ser humano, tornando-o expoente de um bem-estar integral. Tudo isso não é um excesso, mas uma necessidade daquela virtualidade que o homem é.

O valor da "sociabilidade" contém os conceitos profundos de "política", "civitas", por conseguinte, o indivíduo não só homem (a humanidade em sentido geral) e pessoa (ser individuado), mas também cidadão.

Na Itália, o conceito de "cidadania" era claro e distinto já em 1300, 1400: o que é o Estado, quais são os direitos e deveres, qual é o modo - segundo a possibilidade prática - para tornar melhor a sociedade, qual é o valor da família, da pátria etc. No final o grande valor é o homem, a pessoa, o indivíduo (MENEGHETTI, 2010, p. 58, grifos do autor, tradução nossa).

No começo deste ano de 2016, iniciou-se um ciclo de encontros com cerca de trinta famílias de baixa renda com o intuito de trabalhar os quatro valores do humanismo histórico apontados por Meneghetti: vida ativa, sociabilidade, liberdade e dignidade do homem, sob a forma de temas referentes à cidadania e responsabilização quanto aos seus deveres, consigo mesmo, com a sua família, vizinhos e sociedade. Ao realizar o planejamento dos encontros, a dúvida foi: por onde começar? Qual tema, qual aspecto eleger para dar início aos encontros e, a partir dele, encadear outros temas? A resposta foi uma só, começar pelo início, pelo princípio primeiro que constitui o homem: a psique, a inteligência, a alma, a essência do humano, por aquela virtualidade que o homem é. De modo simples e elementar, construiu-se junto com os participantes uma definição de "alma" e quais os comportamentos e atitudes que enaltecem ou ferem a dignidade como seres humanos. Entre tantos pontos, ressaltou-se o cuidado com o 
próprio corpo, que é a primeira morada da alma. Cuidado com a higiene pessoal, alimentação, saúde, ressaltando a responsabilidade pessoal com esses cuidados.

A forma de iniciar a pedagogia dessas pessoas foi, primeiramente, a responsabilização quanto à participação ativa nos encontros, manifestando-se, opinando sobre temas de seu interesse e contribuindo com os temas abordados. Os presentes foram incentivados a manifestar-se, a expor seus conhecimentos, suas ideias, a usar seu intelecto para elaborar respostas, posicionamentos, argumentações, sair da posição cômoda de apenas ouvir, às vezes, até sem prestar atenção no que está sendo dito. Abordou-se a responsabilização em relação ao uso da própria capacidade intelectual, sair da posição de intelecto passivo para a de intelecto agente. Concomitante a isso, fezse pedagogia quanto a outras atitudes necessárias à vida em sociedade e que, no início, não eram observadas, tais como: esperar pela sua vez de falar, ouvir com respeito, não rir das respostas dos outros e até coisas muito elementares como não falar ao telefone durante os encontros. Parecem coisas banais, ou tidas como subentendidas, mas, na prática, constatou-se que até mesmo esses aspectos elementares nunca foram ensinados e as regras de boa convivência, a gentileza, o refinamento no trato, que tornam as relações agradáveis e enaltecem a dignidade humana não fazem parte da vida de um grande contingente de cidadãos.

A educação dos filhos foi mais um dos temas abordados, uma vez que se constata pouco empenho ou desconhecimento dos pais sobre como educar os seus filhos para serem cidadãos protagonistas e responsáveis pela condução da própria vida. Primeiro ponto tratado: educa-se com o exemplo, com isso, explicitando que o que se ensina aos filhos deve-se adotar como postura pessoal. Em seguida, ressaltando a necessidade de responsabilizar os filhos pela execução de pequenas tarefas domésticas que devem ser feitas com seriedade e máximo de empenho, de acordo com as possibilidades de cada um. Ensinando-se, desse modo, como investir de modo sério o próprio potencial, nas pequenas coisas do dia a dia, que se denomina miricismo cotidiano, pois é, assim, que a pessoa constrói-se.

Discutiu-se a importância do trabalho como forma de possibilitar o ganho econômico e, assim, garantir o próprio sustento e também como forma de dar sentido à vida, sentindo-se útil e contribuindo com a sociedade; o trabalho no sentido de vida ativa como um dos valores do humanismo histórico foi outro aspecto abordado no desenrolar dos encontros. Associado a ele, enfocou-se a importância do aprimoramento 
e aprendizagem contínua. A aprendizagem que se dá não tanto no sentido do estudo formal, mas principalmente no sentido de aprimorar-se nas pequenas coisas feitas no dia a dia, pois, como indica Meneghetti (2015, p. 11), deve-se "estudar e trabalhar porque é belo, proporciona prazer e dá uma satisfação total no interior de si mesmo". Sem perder de vista que se trata de famílias em situação de grande pobreza e que vivem em condições bastante precárias, o estímulo foi no sentido de fazer melhor e aprimorar as pequenas coisas que estão ao seu alcance, como o preparo das refeições, a organização e limpeza da moradia, a limpeza e embelezamento dos arredores da casa.

\section{Resultados}

Os resultados do trabalho, embora modestos e incipientes, são perceptíveis em pequenas ações. Pouco a pouco, a atitude inicial de desleixo, seja com o modo de vestir, de portar-se uns com os outros e com a palestrante alterou-se. Percebe-se um cuidado maior com a higiene pessoal, com o modo de vestir, as mesmas roupas simples, porém limpas, bem conservadas e escolhidas com cuidado, além de zelo no modo de falar, adequando o tom de voz, esperando o momento de falar e ouvindo com atenção o outro. Atitudes que demonstram maior consciência e respeito consigo mesmo e com os demais.

A técnica de promover a participação ativa durante os encontros foi tão significativa que uma das participantes manifestou: "então, o que a senhora quer é que a gente use a própria cabeça?” E as manifestações que a princípio eram tímidas e esparsas tornaram-se mais frequentes e qualificadas. $\mathrm{O}$ estímulo à manifestação, o respeito e a valorização das falas e posicionamentos encorajou-os a expor as suas ideias e levou-os a constatar não só que são capazes de pensar e expressar-se, mas também que o que expressam tem valor. Outra estratégia utilizada foi responsabilizar três jovens a pesquisar brevemente sobre o significado de dignidade humana. Foi belo ver o empenho e a preocupação em cumprir com a tarefa que receberam, pesquisando na internet, solicitando a impressão do conceito encontrado e apresentado orgulhosamente para o grupo.

Com relação ao trabalho e ao próprio sustento, também há resultados demonstrados, em especial, entre os mais jovens, que, no início, não tinham nenhuma fonte de renda e, atualmente, estão desempenhando atividade remunerada e tornando-se 
modestamente autônomos. Dois casos sobressaem-se: uma jovem, mãe de duas adolescentes, que, com orgulho, solicitou o desligamento do programa de complementação alimentar, pois já ganha o suficiente para adquirir os alimentos por conta própria; outra jovem, com uma filha, que recebeu incentivo para a produção de uma horta doméstica e, hoje, vende as hortaliças produzidas, com entregas semanais a clientes fiéis, tornando-se uma referência para muitos consumidores. Ambas são chefes de família e únicas responsáveis pelo sustento dos filhos.

\title{
CONSIDERAÇÕES FINAIS
}

No entendimento de Meneghetti:

\begin{abstract}
O verdadeiro homem não tem necessidade da piedade, da caridade e do sacrifício de outro, tem muito orgulho e muita divindade autônoma naquele coração em que está presente o reino dos céus. Deve-se, portanto, suscitar, despertar esse original que está sufocado por tantas próteses culturais e históricas, por tantos sobrepostos estereótipos etc. é necessário recuperar o homem novo e sepultar com decência o homem velho, "velho" porque sufocado por demasiadas próteses (MENEGHETTI, 2015, p. 13).
\end{abstract}

$\mathrm{Na}$ perspectiva de despertar o verdadeiro potencial existente em cada um e, com isso, fazendo-os acreditar em si mesmo e na sua capacidade, procura-se responsabilizar a pessoa pela transformação da sua realidade. Verifica-se, muitas vezes, o descrédito em si mesmo, a pessoa considera-se incapaz de conseguir uma colocação no mercado de trabalho, de garantir o próprio sustento, de alcançar boas notas na escola ou, por outro lado, culpa o sistema por não lhe dar as devidas oportunidades. No entanto, o que se observa é que as oportunidades existem para todos, mas a pessoa não se preparou devidamente, ou não está disposta, devido à acomodação, a fazer o empenho necessário para aproveitá-las. Segundo as oportunidades históricas de cada um, procura-se incrementar não só o dever, mas também o direito ao autodesenvolvimento e consequente maior bem-estar e sentido de satisfação com a própria vida, contribuindo para a construção de um novo humanismo, conforme as premissas de cidade educadora.

Os princípios das Cidades Educadoras preconizam a contextualização mais ampla do caráter educativo, neste sentido, convergem com as diretrizes da intersetorialidade e do trabalho em rede da política de assistência social. No ano de 
2015, o trabalho com os usuários contemplou bastante esse aspecto, com a participação de profissionais de diversos setores do poder público e de outras instituições da rede socioassistencial. O ano de 2016 focou mais no princípio da cidade educadora como promotora da participação cidadã, crítica e responsável. Na continuidade do trabalho, buscar-se-á integrar mais esses dois aspectos, intensificando a participação de profissionais da rede socioassistencial.

\section{REFERÊNCIAS}

ASSOCIAÇÃO INTERNACIONAL DE CIDADES EDUCADORAS. Rede Brasileira. Cidades Educadoras. Disponível em: $<$ http://www.cidadeseducadorasbrasil.net.br/Cidade-Educadora.aspx $>$. Acesso em: 2 out. 2016.

BENELLI, S. J. As éticas nas práticas de atenção psicológica.Estudos de Psicologia, abr./jun. p. 269-287.

BRASIL. Política Nacional de Assistência Social. Brasília: 2005.

BRASIL.Lei $n^{o}$ 8.742, de 7 de dezembro de 1993. Brasília: Ministério do Desenvolvimento Social e Combate à Fome, 2012.

CARTA DAS CIDADES EDUCADORAS. Genova: 2004. Disponível em: $<$ http://comunidadesdeaprendizagem.org.br/Cartadascidadeseducadoras.pdf>. Acesso em: 2 out. 2016.

GADOTTI, Moacir. A escola na cidade que educa. Cadernos CENPEC, v. 1, n. 1. São Paulo: 2006. Disponível em: <http://cadernos.cenpec.org.br/cadernos/index.php/cadernos/article/view/160>. Acesso em: 13 out. 2016.

MAY, R.A descoberta do ser. Rio de Janeiro: Rocco, 1988.

MENEGHETTI, A.Manual de Ontopsicologia. Recanto Maestro: Ontopsicologica, 2004.

MENEGHETTI, A. As raízes da pobreza. Entrevista à Revista Performance Líder. São Paulo: Ontopsicologica, Junho 2010.

MENEGHETTI, A.Dall'umanesimo storico all'umanesimo perenne. Roma: Psicologica, 2010.

MENEGHETTI, A.Pedagogia ontopsicológica. 3 ed. ed. Recanto Maestro: Ontopsicológica Editora Universitária, 2014.

MENEGHETTI, A.Arte, sonho e sociedade. Recanto Maestro: Ontopsicológica Editora Universitária, 2015. 
Saber Humano, ISSN 2446-6298, V. 7, n. 10, p. 76-90, jul./dez. 2017.

SILVA, João Oliveira Correia da.Amartya Sen: liberdade como desenvolvimento. Disponível em <http://www.fep.up.pt/docentes/joao/material/desenv_liberdade.pdf>. Acesso em: 13 out. 2016. 